\title{
Impact of a Dedicated Research Rotation during Ophthalmology Residency
}

\author{
Nita G. Valikodath, $\mathrm{MS}^{1} \quad$ Blake V. Fausett, MD, $\mathrm{PhD}^{1,2}$ Gale A. Oren, MILS ${ }^{1}$ Katherine Whitney \\ Maria A. Woodward, MD, MS 1,3 Shahzad I. Mian, MD ${ }^{1}$ \\ ${ }^{1}$ Department of Ophthalmology and Visual Sciences, University of \\ Michigan Medical School, W. K. Kellogg Eye Center, Ann Arbor, \\ Address for correspondence Shahzad I. Mian, MD, Department of \\ Michigan \\ ${ }^{2}$ Cincinnati Eye Institute, University of Cincinnati School of Medicine, \\ Ophthalmology and Visual Sciences, University of Michigan, 1000 \\ Wall Street, Ann Arbor, MI 48105 (e-mail: smian@umich.edu). \\ Cincinnati, Ohio \\ ${ }^{3}$ Institute for Healthcare Policy and Innovation, University of \\ Michigan, Ann Arbor, Michigan \\ Journal of Academic Ophthalmology 2017;9:e1-e6.
}

\begin{abstract}
\section{Keywords}

- research rotation

- scholarly activity

- residency training

- medical education

Background The Accreditation Council for Graduate Medical Education (ACGME) requires that ophthalmology residents participate in scholarly activity during residency. However, residents lack protected time for research.

Objective This article aims to determine the impact of a dedicated research rotation on scholarly productivity and research experience during residency.

Methods This cohort study compared two groups of ophthalmology residents. Residents who graduated between 2004 and 2009 did not have dedicated research time and served as control residents (CR), while residents who graduated between 2010 and 2015 had a dedicated research rotation and served as the intervention group (research residents, RR). Primary outcomes included publications and presentations recorded over a 4-year period, spanning the 3 years of residency and the first year after graduation. These were analyzed by linear regression and $t$-tests. Residents also took surveys regarding research experience and chi-squared tests and logistic regression were used to compare these results.

Results The RR had 0.97 more publications and 1.3 more presentations compared with the $\mathrm{CR}$ after adjusting for $\mathrm{PhD}$ status, pre-residency publications and presentations, age at graduation, gender, and race $(p=0.09$ and $p=0.02$, respectively). RR had higher odds of reporting adequate time to complete research (odds ratio $[\mathrm{OR}]=13.11,95 \%$ confidence interval $[\mathrm{Cl}]: 3.58-48.03, p<0.001)$ and satisfaction with their research experience $(\mathrm{OR}=6.96,95 \% \mathrm{Cl}=2.104-23.053, p=0.002)$.

Conclusion Residents with a research rotation had more time to complete research, were more satisfied with their research experience, and generated more publications and presentations compared with residents without the research rotation. A research rotation can help meet ACGME requirements and help residents achieve greater scholarly activity.
\end{abstract}

received

August 29, 2016

accepted after revision

December 2, 2016
DOI http://dx.doi.org/

10.1055/s-0037-1599078. ISSN 2475-4757.
Copyright $\odot 2017$ by Thieme Medical Publishers, Inc., 333 Seventh Avenue, New York, NY 10001, USA. Tel: +1(212) 584-4662.
License terms

(c) (i) $\ominus$ (\$) 
While it seems intuitive that ophthalmic research should be driven by ophthalmologists, an increasing proportion of ophthalmologists are not pursuing an academic career. ${ }^{1}$ Over the past few decades, the overall number of physicians with active research careers has declined. ${ }^{2,3}$ Fewer physicians are engaging in research because of economic disincentives, including medical school costs, income disparities between researchers and clinicians, and additional training time for specific degrees in research methodologies. ${ }^{4}$

The Accreditation Council for Graduate Medical Education (ACGME) now requires that ophthalmology residency programs have an active research component and that residents participate in scholarly activity. ${ }^{5}$ However, residents lack the time to develop research interests during residency. ${ }^{1,6-8}$ Residents have competing educational needs, insufficient funds, a paucity of mentors, inadequate research support, and no organized research curriculum. ${ }^{9-11}$ Studies evaluating the role of research rotations in non-ophthalmology residencies have described several benefits including mild to significant increases in scholarly productivity, as measured by publication and presentation activities. ${ }^{12-16}$ Residents with formal research training and experience have an increased likelihood of obtaining subspecialty fellowship training, academic career appointments, and increased rates of grant procurement and state- and national-based awards during and/or following residency. ${ }^{13,16-22}$ A study of ophthalmologists in New Zealand found that the majority of participants recognized the benefit of research training, including knowledge and skills for conducting research, and abilities to critically analyze the medical literature. $^{12,23,24}$

Based on these reported benefits of formal research training, the University of Michigan Ophthalmology Residency Program initiated a research rotation as part of the curriculum in 2009. Given the lack of literature on the topic in ophthalmology, we assessed the impact of a dedicated research rotation during ophthalmology residency on scholarly activity and research experience.

\section{Methods}

The University of Michigan Institutional Review Board approved the study.

\section{Study Population}

This study examined ophthalmology residents from the Department of Ophthalmology and Visual Sciences at the University of Michigan from 2004 to 2015. The control residents (CR; completion of training between 2004 and 2009) consisted of 37 residents who graduated before implementation of the dedicated research rotation. The research residents (RR; completion of training between 2010 and 2015) consisted of 42 residents who participated in a dedicated research rotation. The research curriculum for the $\mathrm{CR}$ was a mentored research project conducted without dedicated time. Both groups had similar resources for projects, including funding, administrative support for applications, access to statisticians, and permitted time for presentations at national meetings.

\section{Research Rotation}

The research rotation was implemented in 2009 when the residency program increased from six to seven residents per year, which allowed for curriculum redesign and the incorporation of a new rotation. The RR participated in this research rotation, which consisted of a 7-week block during the second year of their ophthalmology residency. The research topic and hypothesis were formulated by the residents and their research mentor. By January of the first year of ophthalmology residency, each resident was required to submit a research proposal with the name of their research mentor and an abstract describing the project and methodology. After the proposal was submitted, the research committee reviewed the projects and gave additional feedback on how to successfully implement the study when necessary during the research rotation. The research mentor was responsible for guidance during the rotation.

\section{Data Collection}

Scholarly productivity was measured by recording resident publications and presentations for a 4-year period including the 3 years of ophthalmology residency and the first year after graduation. Publications were identified by PubMed searches. Presentations were identified from the subjects' curriculum vitae (CV)s and from the Association for Research in Vision and Ophthalmology (ARVO) abstracts search. We recorded pre-residency publications and presentations, doctor of philosophy ( $\mathrm{PhD}$ ) status (in addition to MD), placement in ophthalmology fellowships after graduation, and recipients of Heed Fellowships, which are awarded to exceptional residents to pursue postgraduate fellowships that promote education and research.

\section{Survey}

An anonymous 11-question survey was developed and administered online. The three categories of questions included were (1) basic demographics; (2) postresidency status with regard to employment, awards, and grants; and (3) attitudes toward and influence of the research rotation (for RR) or research experience during residency (for $C R$ ). The questionnaires administered to the two groups were identical with the exception of the use of the term "research rotation" for the RR and "research experience" for the CR.

\section{Statistical Analysis}

Resident characteristics were summarized using means and standard deviations, and frequencies and percentages for categorical variables. Predictors included PhD status, publications and presentations before residency, age at graduation, gender, and race. Multivariable linear regression and independent $t$-tests were used to analyze the primary outcomes of average number of publications and presentations between the two groups. Fellowships and Heed Fellow awardees were also evaluated between the two groups using $t$-tests. Chi-squared tests and logistic regression were used to analyze time for research, interest in future research, confidence in research skills, satisfaction with research experience, and practice setting. Statistical analysis was performed 
Table 1 Characteristics of graduating residents ${ }^{\mathrm{a}}$

\begin{tabular}{|l|l|l|}
\hline & \multicolumn{1}{|l|}{$\begin{array}{l}\text { Control } \\
(n=37)\end{array}$} & $\begin{array}{l}\text { Research } \\
(n=42)\end{array}$ \\
\hline Female (\%) & $9(24.32)$ & $27(64.29)$ \\
\hline Advanced degree (\%) & \multicolumn{2}{|l|}{} \\
\hline PhD & $3(8.11)$ & $9(21.43)$ \\
\hline Other & 10.81 & 19.05 \\
\hline Race (\%) & $26(70.27)$ & $29(69.05)$ \\
\hline White & 0 & $1(2.38)$ \\
\hline African American & $8(21.62)$ & $10(23.81)$ \\
\hline Asian & $1(2.70)$ & $2(4.76)$ \\
\hline Hispanic & $2(5.41)$ & 0 \\
\hline Other & $32.32 \pm 3.14$ & $32.05 \pm 2.27$ \\
\hline Age at graduation ${ }^{\text {b }}$ &
\end{tabular}

Abbreviation: PhD, doctor of philosophy.

${ }^{a}$ Data are displayed as frequency (\%) for all variables except age at graduation.

${ }^{\mathrm{b}} \mathrm{Age}$ at graduation is displayed as mean (standard deviation).

using SAS 9.4 (SAS institute, Cary, NC). A p-value of 0.05 was considered statistically significant.

\section{Results}

Overall, 56 of 79 (70.9\%) residents in the program between 2004 and 2015 responded to the survey, including 34 of 42 (81.0\%) for the RR and 22 of 37 (59.5\%) for the CR. CVs were obtained for 31 (83.8\%) members of the CR and for 42 (100\%) members of the RR. Ninety percent of the CR and RR pursued fellowship training. Demographic data are summarized in -Table 1.

\section{Scholarly Activity}

There was no difference in number of residents with a $\mathrm{PhD}$ between the two groups $(p=0.13)$. Prior to the start of residency, the CR had an average of $2.2 \pm 2.5$ publications compared with the RR with an average of $2.6 \pm 2.4$ pub- lications $(p=0.46)$. The $\mathrm{CR}$ had $1.4 \pm 2.6$ presentations compared with the RR with an average of $2.5 \pm 3.2$ presentations $(p=0.12)$. During residency, the mean number of publications was $2.0 \pm 1.9$ for the CR compared with $3.3 \pm 2.8$ for the RR $(p=0.02)$. The mean number of presentations was $1.8 \pm 1.6$ for the CR compared with $3.4 \pm 2.7$ for the $\mathrm{RR}$ ( $p=0.001$; - Table 2 ). In the multivariable linear regression model adjusting for $\mathrm{PhD}$ status, number of publications and presentations before residency, age at graduation, gender, and race, there were 0.97 more publications per resident and 1.3 more presentations per resident for RR compared with CR ( $p=0.09$ and $p=0.02$, respectively). Presentations before residency were positively associated with both publications and presentations during residency and 1 year after residency $(p=0.002$ and $p=0.01$, respectively; - Table $\mathbf{3}$ ).

RR had higher odds of practicing in an academic setting compared with CR (odds ratio $[\mathrm{OR}]=3.46,95 \%$ confidence interval $[\mathrm{CI}]: 1.12-10.74, p=0.03)$. There was no difference in the subjectively reported number of grants or awards between the RR and the CR (all $p>0.05$ ). The percentage of Heed Fellowship awards was 2.7\% ( 1 of 37 fellows) for the CR compared with $9.5 \%$ for the RR ( 4 of 42 fellows).

\section{Research Experience}

The RR had a higher proportion of positive responses to survey questions regarding time to complete projects, future research interest, confidence in research, and satisfaction with research experience compared with CR (-Fig. 1). Of the $\mathrm{CR}, 59 \%$ disagreed that they had protected time to conduct research compared with $0 \%$ of $\mathrm{RR}(p<0.001)$. In the CR group, only $23 \%$ felt they had time to complete projects compared with $79 \%$ in the RR $(p<0.001)$. RR had 13.11 times higher odds of reporting adequate time to complete research projects compared with the $C R(O R=13.11,95 \%$ $\mathrm{CI}=3.58-48.03, p<0.001)$.

The CR and the RR had significant differences in their confidence to conduct research $(p=0.03)$. Of the CR, 31.8\% reported that their confidence increased during their residency training period as compared with $58.8 \%$ of the RR. The RR had higher odds of satisfaction with their research

Table 2 Scholarly activity during residency training

\begin{tabular}{|c|c|c|c|}
\hline & Control $(n=37)$ & Research $(n=42)$ & $p$-Value $(95 \% \mathrm{Cl})$ \\
\hline \multicolumn{4}{|l|}{ Publications } \\
\hline Mean (SD) & $2.00(1.89)$ & $3.33(2.81)$ & $\begin{array}{l}0.0146 \\
(2.0917,2.8745)\end{array}$ \\
\hline Median (IQR) & $2(0-3)$ & $3(1-5)$ & \\
\hline Range & $0-7$ & $0-11$ & \\
\hline \multicolumn{4}{|l|}{ Presentations } \\
\hline Mean (SD) & $1.76(1.57)$ & $3.40(2.71)$ & $\begin{array}{l}0.0013 \\
(1.9467,2.6752)\end{array}$ \\
\hline Median (IQR) & $1(1-3)$ & $3(1-4)$ & \\
\hline Range & $0-5$ & $0-14$ & \\
\hline
\end{tabular}

Abbreviations: $\mathrm{Cl}$, confidence intervals; IQR, interquartile range; SD, standard deviation. 
Table 3 Multivariable linear regression model for average number of publications and presentations ${ }^{\mathrm{a}}$

\begin{tabular}{|l|l|l|l|l|}
\hline \multirow{2}{*}{} & Publications & \multicolumn{2}{l|}{ Presentations } \\
\cline { 2 - 5 } & Standardized coefficient $(\beta)$ & $p$ & Standardized coefficient $(\beta)$ & $p$ \\
\hline Research group (vs. control) & 0.97 & 0.09 & 1.3 & 0.02 \\
\hline Female (vs. male) & 0.14 & 0.81 & 0.16 & 0.79 \\
\hline Age at graduation (per year increase) & 0.01 & 0.90 & -0.08 & 0.46 \\
\hline Race & -0.47 & 0.41 & -0.03 & 0.96 \\
\hline PhD (vs. none) & -0.71 & 0.43 & -0.63 & 0.47 \\
\hline Pre-residency publications & 0.13 & 0.37 & 0.12 & 0.38 \\
\hline Pre-residency presentations & 0.38 & 0.002 & 0.31 & 0.01 \\
\hline
\end{tabular}

Abbreviations: $\mathrm{Cl}$, confidence interval; $\mathrm{PhD}$, doctor of philosophy.

${ }^{a}$ Multivariable linear regression model adjusted for all other variables in the table.

'The referent category was non-Caucasian.

experience compared with the $\mathrm{CR}(\mathrm{OR}=6.96,95 \% \mathrm{Cl}$ $=2.104-23.053, p=0.002$ ). The RR also had a $240 \%$ higher odds of interest in conducting research in the future compared with the CR $(\mathrm{OR}=3.40,95 \% \mathrm{CI}=1.02-11.32$, $p=0.046$ ). Of the RR, $70.6 \%$ felt that the research rotation was valuable and $61.8 \%$ of the RR believed that the research rotation should be mandatory.

\section{Discussion}

Our study was the first to show that a resident research rotation in ophthalmology is beneficial in terms of scholarly productivity and resident research experience. In the unadjusted analysis, residents with a 7-week research rotation had twice as many publications and presentations compared with those without dedicated time. The difference between the two groups was significant for presentations but not publications. After adjusting for a PhD background, scholarly work before residency, age at graduation, gender, and race, the research rotation continued to have a positive impact on scholarly productivity, with more publications and presen-

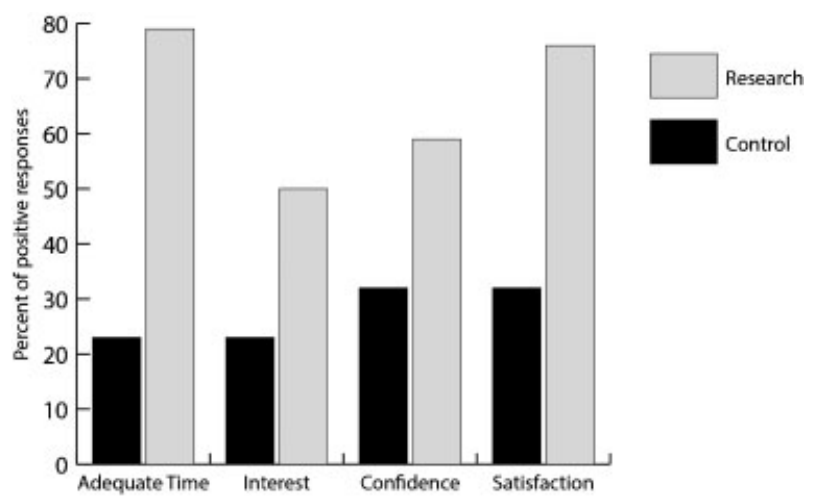

Fig. 1 Research experience among control and research groups. Distribution of positive survey responses was compared between the control and the research groups. Positive survey responses were "agree" for time, interest, and satisfaction (vs. "disagree" and "neutral") and "increased" for confidence (vs. "stayed the same" and "decreased"). $N=22$ for control group and $n=34$ for research group. tations by residents with a dedicated research rotation. Perhaps the research rotation allotted residents time to complete presentations, which require less rigor, time, and involvement than publications. Other fields of medicine, including internal medicine and psychiatry, have shown similar outcomes of increased resident scholarly productivity. ${ }^{25,26}$ Although the majority of ophthalmology residents in both groups pursued fellowship opportunities, the RR were more likely to hold academic positions after residency and were awarded more Heed Fellowships.

The resident research rotation during ophthalmology residency demonstrated clear advantages not only in scholarly activity but also in the research experience for the residents. Characteristics of a successful research curriculum in a training program include time to conduct research, resources to conduct the research, and opportunities to present research. ${ }^{27}$ In our study, RR were more likely to feel that they had adequate time to complete research projects during residency and were more satisfied with their research experience. This may explain their increased interest to continue research after residency training compared with residents who did not have dedicated research time. Fraker et al studied a research experience of shorter duration compared with our study and found that a dedicated research experience could increase confidence and the desire to conduct future research. ${ }^{28}$

Having a PhD degree did not appear to impact scholarly activity between the RR and the CR. After controlling for PhD status in the multivariable model, a statistically significant difference in publications and presentations was still detected. There are increasingly less physician-scientists in the field, given the demands and constraints of a career that balances clinical care and research, including developing expertise, funding, and time. The need for physician-scientists is likely to grow though, given the advancements in medicine and demand to apply these discoveries into clinical practice. ${ }^{29}$ Early exposure to research in less time-intensive ways, such as presentations before residency, was associated with more publications and presentations during residency and 1 year after. Exposure through presentations before residency likely 
drives interest and pursuit of scholarly activity during residency.

The resident research rotation also helped meet ACGME requirements for research during ophthalmology residency. This includes curriculum requirements for training in basic principles of research, such as how research is conducted, evaluated, and explained to patients and applied to patient care. ${ }^{5}$ The programs also have to provide resources necessary to conduct scholarly activities. These requirements are assessed annually through the ACGME Accreditation Data System, where individual resident publications and presentations are reported. In addition, pursuit of scholarly activity is also assessed through the annual resident and faculty surveys.

Limitations of the study included a small sample size in the control and research groups as well as few $\mathrm{PhD}$ residents in both groups. The location of residency training at an academic institution could imply that residents in the control group have a higher baseline involvement with research, limiting the generalizability of the study. CVs were unattainable from six members of the control group, which precluded a more thorough search of presentations for those residents. We evaluated publications and presentations over a short, 4year duration, 3 years during ophthalmology residency and 1 year after residency. Expanding beyond 1 year after residency could capture more publications that were in progress at the time of residency. The RR were more recent graduates than the CR by design of the study, which means that the time period differences could introduce recall bias in survey responses and affect results such as awards/grants and academic positions, where older graduates (CR) will have had more time to obtain awards/grants and change positions.

In addition, the training environment itself can change over time, which could possibly influence scholarly productivity in general. At this institution, the faculty increased from 56 in 2004 to 93 in 2015, which has resulted in increased academic productivity as a department. Future work should try to evaluate the influence of mentors on the residents' scholarly productivity. Furthermore, there have been more opportunities to present due to an increased number and variety of scientific meetings over time, which could also influence scholarly productivity. Except for a funding increase in 2014, residents' access to scientific meetings was the same for the CR and the RR. All residents received time off and funding to present projects of which they were the primary authors.

\section{Conclusion}

A dedicated research rotation can enhance the research experience during residency training by allowing residents to have protected time to complete research projects, leading to greater productivity. Residents who had a research rotation were more satisfied with their research experience, more confident in their research skills, and interested in continuing research in the future. By implementing a research rotation, ophthalmology residency programs can meet ACGME requirements, train more physician-scientists, increase scholarly productivity, and contribute to a positive research experience for their residents.

\section{Meeting Presentation}

This work was presented at the American Academy of Ophthalmology, Chicago, IL, October 2016.

\section{Financial Support}

The funding organization had no role in the design or conduct of this research. M.A.W. was funded by the National Eye Institute (Bethesda, MD; K23 Mentored Clinical Scientist Award K23EY023596-01). The other authors report no external funding source for this study.

\section{Conflict of Interests}

M.A.W. (Intelligent Retinal Imaging Systems, scientific advisory); these are outside the submitted work. No conflicting relationship exists for the other authors.

\section{References}

1 Weinreb RN, Goldberg JL. Clinician-scientists in ophthalmology revisited. Ophthalmology 2013;120(10):1949-1950

2 Wyngaarden JB. The clinical investigator as an endangered species. N Engl J Med 1979;301(23):1254-1259

3 Ley TJ, Rosenberg LE. The physician-scientist career pipeline in 2005: build it, and they will come. JAMA 2005;294(11): 1343-1351

4 Rosenberg LE. The physician-scientist: an essential-and fragilelink in the medical research chain. J Clin Invest 1999;103(12): 1621-1626

5 Accreditation Council for Graduate Medical Education. ACGME Program Requirements for Graduate Medical Education in Ophthalmology. Available at: http://www.acgme.org/portals/0/ pfassets/programrequirements/240_ophthalmology_2016.pdf. Accessed August 29, 2016

6 Gill S, Levin A, Djurdjev O, Yoshida EM. Obstacles to residents' conducting research and predictors of publication. Acad Med 2001;76(5):477

7 Bammeke F, Liddy C, Hogel M, Archibald D, Chaar Z, MacLaren R. Family medicine residents' barriers to conducting scholarly work. Can Fam Physician 2015;61(9):780-787

8 Rivera JA, Levine RB, Wright SM. Completing a scholarly project during residency training. Perspectives of residents who have been successful. J Gen Intern Med 2005;20(4):366-369

9 Levine RB, Hebert RS, Wright SM. Factors associated with citation of internal medicine residency programs for lack of scholarly activity. Teach Learn Med 2005;17(4):328-331

10 Silcox LC, Ashbury TL, VanDenKerkhof EG, Milne B. Residents' and program directors' attitudes toward research during anesthesiology training: a Canadian perspective. Anesth Analg 2006;102(3): 859-864

11 Vinci RJ, Bauchner H, Finkelstein J, Newby PK, Muret-Wagstaff S, Lovejoy FH Jr. Research during pediatric residency training: outcome of a senior resident block rotation. Pediatrics 2009; 124(4):1126-1134

12 Kanna B, Deng C, Erickson SN, Valerio JA, Dimitrov V, Soni A. The research rotation: competency-based structured and novel approach to research training of internal medicine residents. BMC Med Educ 2006;6:52

13 Hsieh $\mathrm{H}$, Paquette F, Fraser SA, et al. Formal research training during surgical residency: scaffolding for academic success. Am J Surg 2014;207(1):141-145

14 Konstantakos EK, Laughlin RT, Markert RJ, Crosby LA. Assuring the research competence of orthopedic graduates. J Surg Educ 2010; 67(3):129-134 
15 Ozuah PO. Residency research requirement as a predictor of future publication productivity. J Pediatr 2009;155(1):1-2, 2.e1

16 Alguire PC, Anderson WA, Henry RC. Teaching research skills: development and evaluation of a new research program for residents. Teach Learn Med 1993;5(01):37-43. Available at: http:// www.tandfonline.com/doi/abs/10.1080/10401339309539586. Accessed August 29, 2016

17 Cull WL, Yudkowsky BK, Schonfeld DJ, Berkowitz CD, Pan RJ. Research exposure during pediatric residency: influence on career expectations. J Pediatr 2003;143(5):564-569

18 Chang CW, Mills JC. Effects of a reward system on resident research productivity. JAMA Otolaryngol Head Neck Surg 2013; 139(12):1285-1290

19 Byrnes AB, McCormack FX, Diers T, Jazieh AR. The resident scholar program: a research training opportunity for internal medicine house staff. J Cancer Educ 2007;22(1):47-49

20 Thakur A, Thakur V, Fonkalsrud EW, Singh S, Buchmiller TL. The outcome of research training during surgical residency. J Surg Res 2000;90(1):10-12

21 Ledley FD, Lovejoy FH Jr. Factors influencing the interests, career paths, and research activities of recent graduates from an academic, pediatric residency program. Pediatrics 1993;92(3): 436-441
22 Chan RK, Lockyer J, Hutchison C. Block to succeed: the Canadian orthopedic resident research experience. Can J Surg 2009;52(3): 187-195

23 JayasunderaT,FiskM,McGheeCN.Attitudes to research and research trainingamongophthalmologistsandophthalmologytraineesinNew Zealand.ClinExperimentOphthalmol2003;31(4):294-299

24 Neale AV. A national survey of research requirements for family practice residents and faculty. Fam Med 2002;34(4):262-267

25 Rothberg MB, Kleppel R, Friderici JL, Hinchey K. Implementing a resident research program to overcome barriers to resident research. Acad Med 2014;89(8):1133-1139

26 Tsai AC, Ordóñez AE, Reus VI, Mathews CA. Eleven-year outcomes from an integrated residency program to train research psychiatrists. Acad Med 2013;88(7):983-988

27 DeHaven MJ, Wilson GR, O'Connor-Kettlestrings P. Creating a research culture: what we can learn from residencies that are successful in research. Fam Med 1998;30(7):501-507

28 Fraker LD, Orsay EM, Sloan EP, Bunney EB, Holden JA, Hart RG. A novel curriculum for teaching research methodology. J Emerg Med 1996;14(4):503-508

29 Rubio DM, Primack BA, Switzer GE, Bryce CL, Seltzer DL, Kapoor WN. A comprehensive career-success model for physician-scientists. Acad Med 2011;86(12):1571-1576 